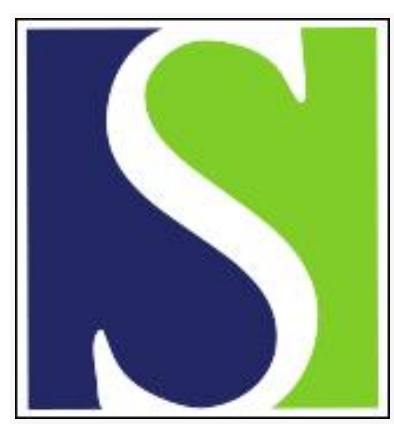

Scand J Work Environ Health 2004;30(6):438-444

https://doi.org/10.5271/sjweh.832

Issue date: Dec 2004

Chronic inflammation induced by organic dust and related metabolic cardiovascular disease risk factors

by Cormier Y, Israël-Assayag E

Affiliation: Hôpital Laval, 2725 Chemin Ste Foy, Ste Foy, Québec, Canada G1V 4G5. yvon.cormier@med.ulaval.ca

Refers to the following text of the Journal: 1999;25(1):39-41

The following article refers to this text: 2004;30(6):421-423

Key terms: C-reactive protein; chronic inflammation; metabolic cardiovascular disease risk; organic dust; swine confinement building; work environment

This article in PubMed: www.ncbi.nlm.nih.gov/pubmed/15633594 


\title{
Chronic inflammation induced by organic dust and related metabolic cardiovascular disease risk factors
}

\author{
by Yvon Cormier, MD, ${ }^{1}$ Evelyne Israël-Assayag, MSc'
}

\begin{abstract}
Cormier Y, Israël-Assayag E. Chronic inflammation induced by organic dust and related metabolic cardiovascular disease risk factors. Scand J Work Environ Health 2004;30(6):438-444.

Objective Chronic inflammation is now considered a risk factor for cardiovascular diseases. Exposure to organic dust induces an inflammatory response. This study was done to verify whether inflammation caused by exposure to organic dust increases the metabolic risk factors for cardiovascular diseases.

Methods Thirty-six nonsmoking men who worked in a swine confinement building and 35 unexposed matched controls were studied. Each person was evaluated for inflammatory markers, including white blood cell counts, cell-bound (CD11b, CD18, CD31, CD62L) and circulating soluble adhesion molecule levels (sICAM-1, sPECAM-1, sL, sE, and sP selectins), serum CRP (C-reactive protein), fibrinogen, and interleukin-6 (IL-6). Cardiovascular risk factors [the serum lipid profile, apoprotein B (Apo B)] and insulin levels were also assessed. Results The groups were similar with respect to age, physical characteristics, and blood cell counts. The expression of adhesion molecules ( $\mathrm{P}$-values $<0.01)$ and serum levels of sL-selectin $(\mathrm{P}<0.0001)$ were higher for the workers than for the controls, while neutrophils and interleukin-6 were slightly higher for the workers $(\mathrm{P}=0.05)$. No differences in $\mathrm{CRP}$, fibrinogen, lipid profile, Apo B, or insulin levels were observed.

Conclusions Exposure to contaminated organic dust induces a chronic inflammation that is not associated with increased metabolic or acute-phase cardiovascular risk factors; this finding suggests that chronic inflammation per se may not be a cardiovascular risk factor in this group of pig farmers.
\end{abstract}

Key terms C-reactive protein; swine confinement building; work environment.

Coronary heart disease has a significant inflammatory component, and chronic inflammation is emerging as yet another risk factor for the development of cardiovascular disease (CVD) $(1,2)$. Acute phase proteins such as C-reactive proteins (CRP) and fibrinogen are closely related to CVD; however, the origin of the systemic inflammation is not always fully known. The release of inflammatory mediators can be initiated in the atherosclerotic plaque itself and thus generate a positive cycle of inflammation-atherosclerosis $(2,3)$. Chronic inflammation can also be driven by infectious processes. (4-8). Whether these associations reflect a cause-effect relationship remains controversial $(9,10)$. Leukocyte count, fibrinogen, and CRP were found to be moderately but highly significantly associated with coronary heart disease in a meta-analysis (11). Other markers of inflammation, including an increased expression of adhesion molecules in cellular interactions that may play a role in the formation of atherosclerotic plaque (12-14) and interleukin-6 (IL-6) blood levels, also correlate with
CVD $(15,16)$. Significant associations have also been reported between classical CVD risk factors such as obesity and dyslipidemic state and elevated plasma concentrations of inflammation markers $(16,17)$.

Studies to date on the role of chronic inflammation in atherosclerosis have focused on endogenous inflammation and infections and on fatty tissue as a source and storage of inflammatory mediators (17). Environmental pollutants can contribute to CVD, possibly by initiating inflammation $(18,19)$. In a review article, Sjögren raised the hypothesis that occupational exposure to dust can be linked with CVD $(20,21)$.

A large number of workers is sometimes exposed to very high levels of organic dust in the workplace. The airborne dust in some of these environments may be contaminated with very high levels of bacteria and fungi that can induce an inflammatory response in humans and animals $(22,23)$.

Swine confinement buildings probably provide a work environment in which the highest levels of exposure are

1 Unité de recherche, Centre de pneumologie (Pulmonary Research Unit). Institut de cardiologie et de pneumologie (Institute of Cardiology and Pneumology), Hôpital Laval. Ste Foy, Québec, Canada.

Reprint requests to: Dr Yvon Cormier, Hôpital Laval, 2725 Chemin Ste Foy, Ste Foy, Québec, Canada G1V 4G5. [E-mail: yvon.cormier@med.ulaval.ca] 
reached. Workers in these buildings are exposed to bacteria, molds, toxic gases, feed particles, animal-derived antigens, and barn dust mites (24). After exposure for a few hours in a swine confinement building, naive volunteers develop a neutrophilia with acute phase cytokine release and neutrophil accumulation in the nasal passages and the lung and an increase in fibrinogen $(25,26)$. Workers' response to daily exposure to swine confinement buildings is much milder than that of formerly unexposed persons, and this difference suggests adaptation to the environment with repeated exposure (27). Workers do, however, develop low-grade chronic airway inflammation (27); it is unknown whether they also experience systemic inflammation that could, in their case, become chronic. These workers therefore represent an interesting model with which to verify the relationship between chronic inflammation and CVD risk factors.

Using the preceding information as a basis, we evaluated workers exposed daily in swine confinement buildings for markers of inflammation and CVD risk factors.

\section{Study population and methods}

\section{Study population}

The study groups consisted of 36 nonsmoking male pig farmers aged 18-55 years and 35 unexposed male referents (controls) of similar ages (table 1). To be eligible for the exposed group, the workers had to work at least 2 hours a day in a swine confinement building, and they had to have been employed in this industry for at least 2 years. The farmers and their controls were free of any medical history of chronic diseases, were not currently taking any medication, and were free of recent viral or bacterial infections (at least 1 month). All of the participants also had to be nonsmokers or ex-smokers for at least 5 years. The farmers were selected from a list of swine producers obtained from the Quebec farmer's union, the "Union des producteurs agricoles" (UPA). The controls were recruited from hospital employees. These employees represented a whole range of professions from physicians to desk clerks and maintenance people, none of whom performed welding or other work that would expose them to a contaminated environment on a regular basis. Each farmer and control signed an informed consent approved by the internal review board of our institution.

\section{Procedures}

A nurse contacted each potential participant by phone to assure their eligibility and willingness to participate and to schedule an appointment for those who agreed to participate. All the solicited farmers and farm hands agreed. The nurse then visited the farmers at home between 0600 and 1000, when they were still fasting and had them sign an informed consent form. She also weighed them, measured their height and waist circumference, and withdrew $45 \mathrm{ml}$ of venous blood. The blood samples were brought to the laboratory within 2 hours of collection. The blood sampling of the controls was performed under the same conditions.

\section{Measured parameters}

Inflammatory markers. White blood cell counts were determined using a Coulter counter (Coulter Electronics of Canada, Burlington, Canada). Soluble selectins (sE, sL, and sP) and soluble intercellular adhesion molecule-1 (sICAM-1) and soluble platelet endothelial cell adhesion molecule-1 (sPECAM-1) were measured using commercially available enzyme-linked immunoabsorbent assay kits (R\&D Systems Minneapolis, MN, USA). Interleukin-6 (IL-6) was measured using highsensitivity determination kits from the same company. The levels of CRP were analyzed by immunonephelometry, and fibrinogen was measured using an automatic coagulation analyzer (Electrea 1600C, Medical Laboratory Automation, Montreal, Canada).

Adhesion molecules. All the antibodies and isotype controls were purchased from Pharmingen, Canada Inc, Mississauga, Ontario. The expression of Mac-1 (CD11b/ CD18), CD31 (PECAM-1), and L-selectin (CD62L) was measured on blood leukocytes. Briefly, $100 \mathrm{ml}$ of whole blood was incubated with phycoerythrin-labeled antibodies or their respective isotype on ice for 45 minutes in the dark. The erythrocytes were lysed with ammonium chloride $(0.14 \mathrm{M})$, washed with phosphate-buffered solution supplemented with $1 \%$ bovine serum albumin and fixed in $2 \%$ paraformaldehyde. The neutrophils, lymphocytes, and monocytes were gated according to

Table 1. Characteristics of the participants. (BMI = body mass index)

\begin{tabular}{|c|c|c|c|c|c|c|c|c|c|c|}
\hline \multirow[t]{2}{*}{ Group } & \multicolumn{2}{|c|}{ Age (years) } & \multicolumn{2}{|c|}{ Weight (kg) } & \multicolumn{2}{|c|}{ Height (cm) } & \multicolumn{2}{|c|}{ Waist size $(\mathrm{cm})$} & \multicolumn{2}{|c|}{ BMI $\left(\mathrm{kg} / \mathrm{m}^{2}\right)$} \\
\hline & Mean & SD & Mean & SD & Mean & $\mathrm{SD}$ & Mean & SD & Mean & SD \\
\hline Controls (35 men) & 37.6 & 1.4 & 75.9 & 1.6 & 174.7 & 1.2 & 84.3 & 1.4 & 24.8 & 2.4 \\
\hline Swine building workers (36 men) & 36.4 & 1.6 & 75.4 & 1.7 & 171.5 & 1.1 & 85.8 & 1.7 & 25.7 & 3.5 \\
\hline P-value & \multicolumn{2}{|c|}{ NS } & \multicolumn{2}{|c|}{ NS } & \multicolumn{2}{|c|}{ NS } & \multicolumn{2}{|c|}{ NS } & \multicolumn{2}{|c|}{ NS } \\
\hline
\end{tabular}


Table 2. Blood cell counts (10\%/l). (WBC = white blood cells)

\begin{tabular}{|c|c|c|c|c|c|c|c|c|c|c|}
\hline \multirow[t]{2}{*}{ Group } & \multicolumn{2}{|c|}{ WBC $\left(10^{9}\right)$} & \multicolumn{2}{|c|}{ Platelets } & \multicolumn{2}{|c|}{ Lymphocytes } & \multicolumn{2}{|c|}{ Monocytes } & \multicolumn{2}{|c|}{ Neutrophils } \\
\hline & Mean & SD & Mean & SD & Mean & SD & Mean & SD & Mean & SD \\
\hline Controls & 5.5 & 0.18 & 240.28 & 10.06 & 1.72 & 0.04 & 0.52 & 0.02 & 3.01 & 0.12 \\
\hline Swine building workers & 5.8 & 0.28 & 219.8 & 7.78 & 1.72 & 0.08 & 0.49 & 0.03 & 3.45 & 0.22 \\
\hline P-value & \multicolumn{2}{|c|}{ NS } & \multicolumn{2}{|c|}{ NS } & \multicolumn{2}{|c|}{ NS } & \multicolumn{2}{|c|}{ NS } & \multicolumn{2}{|c|}{0.05} \\
\hline
\end{tabular}

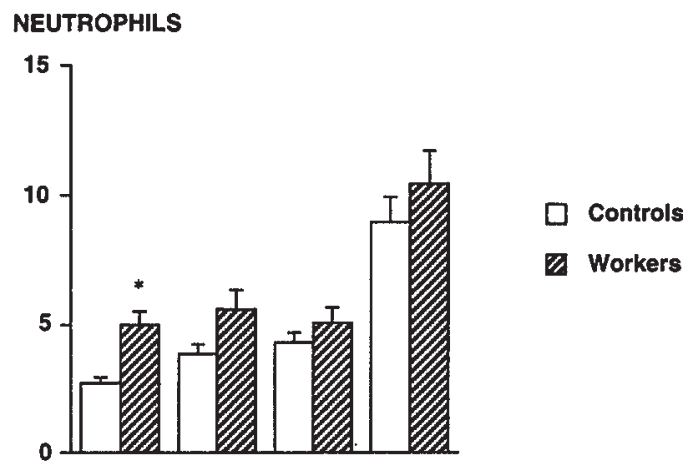

LYMPHOCYTES

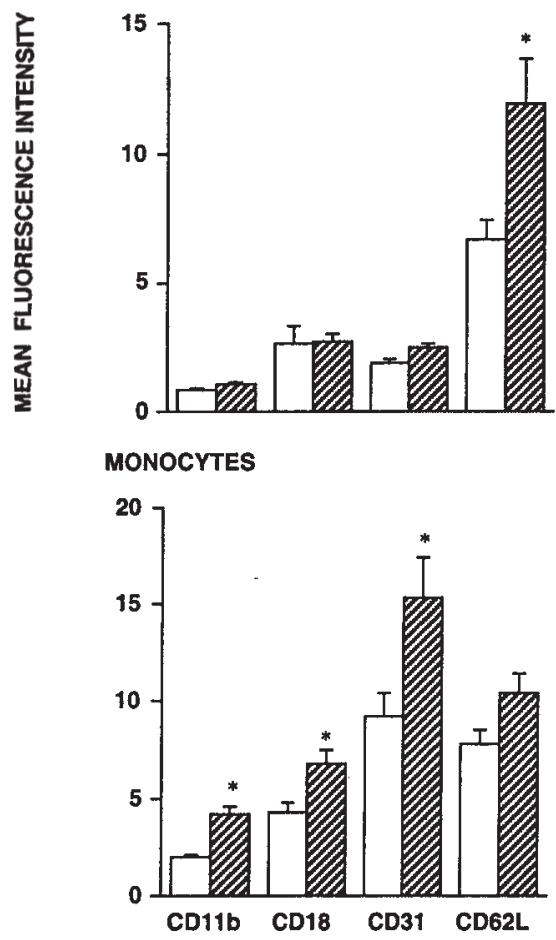

Figure 1. Mean fluorescence intensity of the adhesion molecule expression on peripheral blood neutrophils, lymphocytes, and monocytes for the swine building workers and unexposed normal matched controls. $\left(^{*}=\right.$ significant difference between the swine building workers and controls, $\mathrm{P}<0.05$ )

size and granularity. The analysis was performed with a Coulter EPICS Elite ESP flow cytometer equipped with a 488-nm argon laser (Coulter, Hialeah, FL, USA). The results have been expressed as the mean fluorescent intensities for the different adhesion molecules studied and compared with isotype controls.
Metabolic cardiovascular risk markers. Apoprotein B (Apo-B) levels were obtained by immunonephelometry. Plasma insulin was measured by radioimmunoassay (Diagnostic Systems Laboratories Inc, Webster Texas, TX, USA). The ratio of total cholesterol to high-density lipoprotein (HDL) cholesterol and also triglycerides were determined by standard procedures in the hospital's biochemistry and hematology laboratory.

\section{Statistical analysis}

The measures were expressed as the means and standard deviations. The normality assumption was verified with the Shapiro-Wilk test, and the Brown-Foresythe test was used to verify the homogeneity of the variances. These assumptions were met for Apo B, total cholesterol, low-density lipoprotein (LDL) cholesterol, and the ratio of total cholesterol to HDL cholesterol only. For these parameters, the mean values of the quantitative variables were compared using Student's t-test. For all the other variables, assumptions were unjustified. An alternative procedure that did not depend on these assumptions was used in which the observations were replaced by their rank, called rank transformation, and Student's t-test was applied. This technique is equivalent to performing the Kruskal-Wallis test. The Pearson's correlation coefficient was used to determine the relationship between the variables. Multivariate regression analyses were performed to compare the relationships between the groups. The data were analyzed using the statistical package program SAS (SAS Institute Inc, Cary, NC, USA).

\section{Results}

The characteristics of the participants are presented in table 1. Although we only tried to match the participants for age, both groups turned out to be strikingly similar in body weight and waist circumference. Nor did the white blood cell and platelet counts statistically differ between the swine building workers and the controls (table 2) although a slight increase was observed in the neutrophil cell counts $(\mathrm{P}=0.05)$.

The mean channel fluorescence intensities of each adhesion molecule are given in figure 1 . The expression 
Table 3. Levels of soluble adhesion molecules and inflammatory markers in serum. ${ }^{\text {a }}($ sICAM-1 = soluble intercellular adhesion molecule-1, sPECAM = soluble platelet endothelial cell adhesion molecule-1, IL-6 = interleukin-6, CRP = C-reactive protein)

\begin{tabular}{|c|c|c|c|c|c|c|c|c|c|c|c|c|c|c|c|c|}
\hline \multirow[t]{2}{*}{ Group } & \multicolumn{2}{|c|}{$\begin{array}{l}\text { sE-selectin } \\
\text { (ng/ml) }\end{array}$} & \multicolumn{2}{|c|}{$\begin{array}{l}\text { sL-selectin } \\
\text { (ng/ml) }\end{array}$} & \multicolumn{2}{|c|}{$\begin{array}{l}\text { sP-selectin } \\
\text { (ng/ml) }\end{array}$} & \multicolumn{2}{|c|}{$\begin{array}{l}\text { sICAM-1 } \\
\text { (ng/ml) }\end{array}$} & \multicolumn{2}{|c|}{$\begin{array}{l}\text { sPECAM-1 } \\
\text { (ng/ml) }\end{array}$} & \multicolumn{2}{|c|}{$\begin{array}{c}\mathrm{IL}-6 \\
(\mathrm{pg} / \mathrm{ml})\end{array}$} & \multicolumn{2}{|c|}{$\begin{array}{l}\text { Fibrinogen } \\
\qquad(\mathrm{g} / \mathrm{l})\end{array}$} & \multicolumn{2}{|c|}{$\begin{array}{l}\text { CRP } \\
(\mathrm{mg} / \mathrm{l})\end{array}$} \\
\hline & Mean & SD & Mean & SD & Mean & SD & Mean & SD & Mean & SD & Mean & SD & Mean & SD & Mean & SD \\
\hline $\begin{array}{l}\text { Controls } \\
\text { Swine }\end{array}$ & 37.40 & 2.86 & 871.88 & 25.53 & 272.88 & 14.56 & 245.62 & 10.91 & 27.06 & 1.68 & 1.50 & 0.35 & 3.30 & 0.12 & 1.40 & 0.44 \\
\hline $\begin{array}{l}\text { building } \\
\text { workers }\end{array}$ & 46.27 & 3.63 & 1452.83 & 62.25 & 297.13 & 19.60 & 268.04 & 11.33 & 28.93 & 1.37 & 2.69 & 0.79 & 3.34 & 0.09 & 1.23 & 0.29 \\
\hline P-value & \multicolumn{2}{|c|}{ NS } & \multicolumn{2}{|c|}{$<0.0001$} & \multicolumn{2}{|c|}{ NS } & \multicolumn{2}{|c|}{ NS } & \multicolumn{2}{|c|}{ NS } & \multicolumn{2}{|c|}{0.05} & \multicolumn{2}{|c|}{ NS } & \multicolumn{2}{|c|}{ NS } \\
\hline
\end{tabular}

a Correcting for multiple comparisons by the Bonferroni criteria the P-value for significance is 0.006 .

Table 4. Metabolic risk factor profile. (HDL = high-density lipoprotein, $L D L=$ low-density lipoprotein)

\begin{tabular}{|c|c|c|c|c|c|c|c|c|c|c|c|c|}
\hline \multirow[t]{2}{*}{ Group } & \multicolumn{2}{|c|}{ Triglycerides } & \multicolumn{2}{|c|}{$\begin{array}{c}\text { HDL } \\
\text { cholesterol }\end{array}$} & \multicolumn{2}{|c|}{$\begin{array}{c}\text { LDL } \\
\text { cholesterol }\end{array}$} & \multicolumn{2}{|c|}{$\begin{array}{l}\text { Total cholesterol/ } \\
\text { HDL cholesterol }\end{array}$} & \multicolumn{2}{|c|}{$\begin{array}{c}\text { Apoprotein B } \\
(\mathrm{g} / \mathrm{l})\end{array}$} & \multicolumn{2}{|c|}{$\begin{array}{l}\text { Insulin } \\
(\mathrm{pmol} / \mathrm{l})\end{array}$} \\
\hline & Mean & SD & Mean & SD & Mean & $\mathrm{SD}$ & Mean & SD & Mean & SD & Mean & SD \\
\hline Controls & 1.19 & 0.08 & 1.50 & 0.05 & 3.33 & 0.15 & 3.67 & 0.14 & 1.09 & 0.05 & 32.54 & 4.44 \\
\hline Swine building workers & 1.13 & 0.11 & 1.58 & 0.07 & 3.43 & 0.17 & 3.62 & 0.15 & 1.11 & 0.05 & 31.22 & 6.42 \\
\hline P-value & \multicolumn{2}{|c|}{ NS } & \multicolumn{2}{|c|}{ NS } & \multicolumn{2}{|c|}{ NS } & \multicolumn{2}{|c|}{ NS } & \multicolumn{2}{|c|}{ NS } & \multicolumn{2}{|c|}{ NS } \\
\hline
\end{tabular}

of CD11b molecules on neutrophils were significantly higher for the swine building workers than for the controls $(\mathrm{P}<0.0001)$. Although slightly higher for the swine building workers, the expression of the other adhesion molecules on neutrophils did not differ significantly. The lymphocytes from the swine building workers showed higher levels of CD62L than did those from the controls $(\mathrm{P}=0.0159)$. In the monocyte population, the mean CD11b, CD18, and CD31 expressions were higher for the swine building workers $(\mathrm{P}<0.0001,0.019$, and 0.036 , respectively). Although higher, the expression of $\mathrm{CD} 62 \mathrm{~L}$ did not reach statistical significance $(\mathrm{P}=0.068)$.

Comparative levels of soluble adhesion molecules and IL- 6 are presented for each group in table 3 . The sL-selectin levels of the swine workers workers were almost double those of the controls $(\mathrm{P}<0.0001)$. sE selectin and sICAM-1 were borderline higher in the swine confinement workers, but the difference was not statistically significant $(\mathrm{P}=0.055)$. The levels of sP selectin and sPECAM-1 were comparable. As for serum IL-6, the levels were slightly but not significantly higher in the swine building workers $(\mathrm{P}=0.05)$ than in the controls. No difference in the CRP and fibrinogen levels was observed between the two groups. The metabolic risk factor profile of the two groups is presented in table 4. No difference in the Apo-B and insulin levels was found between the two groups. However, as previously reported (12), significant correlations were found between the CRP values and such cardiovascular risk factors as body weight and waistline ( $\mathrm{r}=0.53$ and 0.62$)$, total-to-HDL-
Table 5. Association between C-reactive protein (CRP) and predictive cardiovascular risk factors. ${ }^{a}(r=$ correlation coefficient, $\mathrm{HDL}=$ high-density lipoprotein)

\begin{tabular}{lrrrrc}
\hline Risk factor & \multicolumn{2}{c}{ Controls } & & \multicolumn{2}{c}{$\begin{array}{c}\text { Swine build- } \\
\text { ing workers }\end{array}$} \\
\cline { 2 - 3 } \cline { 6 - 7 } & $\mathrm{r}$ & $\mathrm{p}$ & & $\mathrm{r}$ & $\mathrm{p}$ \\
\hline Age & 0.197 & $\mathrm{NS}$ & & 0.10 & $\mathrm{NS}$ \\
Weight & 0.529 & 0.001 & & 0.418 & 0.01 \\
Waistline & 0.621 & 0.0001 & & 0.367 & $<0.05$ \\
Total- to HDL-cholesterol ratio & 0.420 & 0.012 & & 0.253 & $\mathrm{NS}$ \\
Triglycerides & 0.528 & 0.001 & & 0.337 & $<0.05$ \\
Apoprotein B & 0.069 & $\mathrm{NS}$ & & 0.252 & $\mathrm{NS}$ \\
Fibrinogen & 0.783 & $<0.001$ & & 0.380 & $\mathrm{NS}$ \\
Insulin & 0.367 & $<0.05$ & & 0.168 & $\mathrm{NS}$ \\
\hline
\end{tabular}

a When corrected for multiple comparisons by the Bonferroni criteria, the P-value for significance is 0.006 .

cholesterol ratio and triglycerides ( $\mathrm{r}=0.42$ and 0.53$)$, fibrinogen ( $\mathrm{r}=0.78)$, and insulin ( $\mathrm{r}=0.36)$ (table 5). Among the swine building farmers, the correlations were weaker for the obesity markers, and the CRP levels did not correlate with usual risk factors such as fibrinogen, insulin, and soluble P-selectin. Similarly a stronger correlation was noted between the CRP concentrations and the plasma IL-6 and sP-selectin levels of the controls (table 6). The plasma levels of sICAM-1, a good predictive marker of inflammation, correlated better with CRP among the swine building workers than among the controls (table 6). No correlation was found with the other circulating soluble adhesion molecules. The interactions between the groups were not significant (data not shown). 
Table 6. Association between C-reactive protein (CRP) and inflammatory markers. ${ }^{a}(r=$ correlation coefficient, ICAM- $1=$ intercellular adhesion molecule-1, IL-6 = interleukin-6)

\begin{tabular}{lrrrrr}
\hline Marker & \multicolumn{2}{c}{ Controls } & & \multicolumn{2}{c}{$\begin{array}{c}\text { Swine building } \\
\text { workers }\end{array}$} \\
\cline { 2 - 3 } \cline { 5 - 6 } & \multicolumn{1}{c}{$r$} & $\mathrm{p}$ & & $\mathrm{r}$ & $\mathrm{p}$ \\
\hline Soluble E-selectin & 0.140 & $\mathrm{NS}$ & & 0.281 & $\mathrm{NS}$ \\
Soluble L-selectin & -0.008 & $\mathrm{NS}$ & & 0.112 & $\mathrm{NS}$ \\
Soluble P-selectin & 0.435 & $<0.01$ & & -0.037 & $\mathrm{NS}$ \\
Soluble ICAM-1 & 0.318 & 0.06 & & 0.442 & $<0.01$ \\
IL-6 & 0.579 & $<0.005$ & & 0.315 & 0.06 \\
\hline
\end{tabular}

a When corrected for multiple comparisons by the Bonferroni criteria the P-value for significance is 0.01 .

\section{Discussion}

Our objective in this study was to verify whether workers exposed to a highly contaminated environment inducing a chronic inflammatory response would be characterized by an atherogenic CVD risk profile. On the basis of the high levels of bacteria and endotoxins generally found in swine confinement buildings, the known acute pro-inflammatory effect of exposure in swine confinement buildings, and the similarities between the two study groups, except for their exposures, we can assume that the observations made are related to the workplace. Although there is no perfect control group, we believe the one we used, which consisted of a variety of hospital workers, was appropriate. The results of their blood analysis support this opinion. The most important difference between the workers and the controls was the exposure of the former in a highly contaminated environment.

This study showed that the pig farmers had clear signs of chronic inflammation in peripheral blood, as shown by an increased expression of adhesion molecules on blood leukocytes and circulating soluble L-selectin. The adhesion molecule expression is increased in atherosclerosis (28), and levels of soluble adhesion molecules in plasma, including soluble vascular cell adhesion molecule-1 (sVCAM-1), are similarly increased after a cardiovascular event (29). It is still unclear whether these molecules have a predictive value for CVD risk, however. A large-scale epidemiologic survey measuring adhesion molecules in up to 20-year-old sera showed a limited prognostic value for CVD (30). However contrasting results were obtained by Blankenberg et al (31), who showed that SVCAM-1 concentrations had a strong predictive value in determining the risk of future cardiovascular death (31). Methodological issues and the limitations of large-scale epidemiologic studies may explain the discrepancies.

However, in this study, despite the differences in inflammation markers, no difference was found between the two groups with respect to the total white blood cell counts and the metabolic CVD risk factor profile, including the absence of differences in the fasting plasma lipid profile and in plasma Apo-B, fibrinogen and insulin levels. Furthermore, despite differences in IL-6, the prime regulator of hepatic CRP production (32), no difference in plasma CRP levels were found between the two groups.

The low-grade neutrophilia can probably be explained by the fact that workers were examined in the morning, 12 to 15 hours after their last exposure. Although some of them had spent a short period of time in a swine confinement building before the blood collection, the duration of that exposure had probably been too short to induce a measurable inflammatory response. We had specifically designed our study so that the blood samples would be taken in the morning, at a time when the lowest point of inflammation due to exposure should be expected. The fact that we could still identify markers of inflammation strongly suggests that these workers were characterized by a chronic inflammatory state.

By the nature of the inflammatory stimulus, our study represents a relevant model for sorting out the independent contribution of inflammation per se to the development of an atherogenic metabolic risk profile. The results clearly indicate that chronic inflammation, as seen in swine confinement workers, is not sufficient to induce the development of insulin resistance (as crudely reflected by plasma insulin levels) or an atherogenic dyslipidemic profile.

Despite the lack of difference in the CRP levels between the two groups, very significant positive correlations were found between the CRP levels and several markers of an atherogenic metabolic profile, including abdominal obesity, triglycerides, and elevated IL- 6 concentrations. One worker had high levels of both CRP and IL-6; a subanalysis without this worker did not change the high significance between these two parameters in the control group. This finding suggests that the added inflammation induced by the swine building exposure did not contribute to the classical CVD risk profile. Whether or not a chronic inflammation without changes in currently known CVD risk factors could be an independent risk factor remains unknown. However, it seems reasonable to suggest that an inflammatory profile such as the one found for pig farmers may not be an independent CVD risk factor. If the inflammation caused by swine building exposure is a risk factor, it would have to be via other metabolic profiles than those currently known to be implicated in CVD.

Previous studies on the risk of CVD in farmers have reported equivocal results. One study showed an increased risk for younger farmers, while others have shown equal or lower incidence rates of heart diseases among farmers (33-35). Obviously, concomitant variations in 
numerous CVD risk factors could explain the differences among studies. Female farmers in eastern Finland had higher plasma levels of fibrinogen and also an increased risk of coronary deaths after adjustment for age, smoking, serum cholesterol, and systolic blood pressure (36). Swedish male farm managers and supervisors had an increased risk of myocardial infarction after adjustment for age, country, and socioeconomic group (37). The causes of these differences are unknown. Two recent cohort studies reported an increased risk for CVD among farmers (RR 1.4, 95\% CI 1.2-1.7) in a comparison with all other adult workers in the United States (38) and an increased proportionate mortality ratio for myocardial infarction in farmers (39). However, none of these studies linked the increased risk of CVD with inflammation related to the work environment. Other causes, such as diet and farming stress, could also be contributing factors.

Our findings in a small group of workers showed that chronic exposure to an environment that induces chronic inflammatory indices is insufficient to generate the altered metabolic profile currently known to predict an increased risk of CVD. Thus we can assume that inflammation, measured by the increase of cell-bound adhesion molecules, sL-selectin and IL-6, in the absence of a clear increase in traditional inflammatory markers such as white blood cell count, CRP, and fibrinogen, is not a CVD risk factor for these workers. The origin of the low-grade inflammation associated with increased risks of CVD is still unclear; one study of 155 twin pairs suggested that CRP levels may be under significant genetic control (40). However these genetic factors may interact with environmental and perhaps also with dietary factors to induce a sustained low-grade harmful inflammation (41). Additional large-scale studies are needed to verify whether the type of inflammation induced by contaminated environments could represent an independent CVD risk.

\section{References}

1. Ridker PM. Inflammation, atherosclerosis, and cardiovascular risk: an epidemiologic view. Blood Coagul Fibrinolysis 1999; 10 Suppl 1:S9-12.

2. Ross R. Atherosclerosis—an inflammatory disease. N Engl J Med 1999;340:115-26.

3. Capron L. Étiologie de l'athérosclérose. Rev Prat 1999; 49:2100-03.

4. Haider AW, Larson MG, O'Donnell CJ, Evans C, Wilson PW, Levy D. The association of chronic cough with the risk of myocardial infarction: the Framingham Heart Study. Am J Med 1999;106:279-84.

5. Jousilahti P, Vartiainen E, Tuomilehto J, Puska P. Symptoms of chronic bronchitis and the risk of coronary disease. Lancet 1996;348:567-72.
6. Beck JD, Pankow J, Tyroler HA, Offenbacher S. Dental infections and atherosclerosis. Am Heart J 1999;138:S528-33.

7. Davidson M, Kuo CC, Middaugh JP, Campbell LA, Wang SP, Newman WA 3rd, et al. Confirmed previous infection with chlamydia pneumonia (TWAR) and its presence in early coronary atherosclerosis. Circulation 1998;98:628-33.

8. Mendall M, Goggin P, Levy J, Malineaux N. Relation of helicobacter pylori infection and coronary heart disease. $\mathrm{Br}$ Heart J 1994;71:437-9.

9. Hoffmeister A, Rothenbacher D, Wanner P, Body G, Persson $\mathrm{K}$, Brenner H, et al. Seropositivity to chlamydial lipopolysaccharide and chlamydia pneumonia, systemic inflammation and stable coronary artery disease: negative results of a casecontrol study. J Am Coll Cardiol 2000;31:112-8.

10. Koenig W, Rothenbacher D, Hoffmeister A, Miller M, Bode G, Alder G, et al. Infection with Helicobacter pylori is not a major independent risk factor for stable coronary heart disease: lack of a role of cytokin-associated protein A-positive strains and absence of a systemic inflammatory response. Circulation 1999;100:2326-31.

11. Danesh J, Collins R, Applyby P, Peta R. Association with fibrinogen, C-reactive protein, albumin, or leukocyte count with coronary heart disease. JAMA 1998;279:1477-82.

12. Sullivan GW, Sarembock IJ, Linden J. The role of inflammation in vascular diseases. J Leukoc Biol 2000;67:591-602.

13. Cybulsky MI, Lichtman AH, Hajra L, Iiyama K. Leukocyte adhesion molecules in atherogenesis. Clin Chim Acta 1999;286:207-18.

14. Chia MC. The role of adhesion molecules in atherosclerosis. Crit Rev Clin Lab Sci 1998;35(6):573-602.

15. Mendall MA, Patel P, Asante M, Ballam L, Morris J, Strachan $\mathrm{DP}$, et al. Relation of serum cytokine concentrations to cardiovascular risk factors and coronary heart disease. Heart 1997;78:273-7.

16. McCarthy MF. Interleukin- 6 as a central mediator of cardiovascular risk associated with chronic inflammation, smoking, diabetes, and visceral obesity: down-regulation with essential fatty acids, ethanol and pentoxifylline. Med Hypotheses 1999;52:465-77.

17. Rohde LE, Hennekens CH, Ridker PM. Survey of C-reactive protein and cardiovascular risk factors in apparently healthy men. Am J Cardiol 1999;84(9):1018-22.

18. Peters A, Doring A, Wichmann HE, Koenig W. Increased plasma viscosity during an air pollution episode: a link to mortality? Lancet 1997;349:1582-7.

19. Seaton A, MacNee W, Donaldson K, Godden D. Particulate air pollution and acute health effects. Lancet 1995;345:176-8.

20. Sjögren B. Occupational exposure to dust: inflammation and ischemic heart disease. Occup Environ Med 1997;54:466-9.

21. Sjögren B, Weiner J, Larsson K. Ischaemic heart disease among livestock and agricultural workers [electronic journal]. Occup Environ Med. 2003 Aug;60(8):e1.

22. O'Grady NP, Preas HL, Pugin J, Fiuza C, Tropea M, Reda D, et al. Local inflammatory responses following bronchial endotoxin instillation in humans. Am J Respir Crit Care Med 2001;163:1591-98.

23. Fogelmark B, Sjöstrand M, Rylander R. Pulmonary inflammation induced by repeated inhalation of $\mathrm{B}(1,3)$-D-Glucan and endotoxin. Int J Exp Pathol 1994;75:85-90.

24. Clark S, Rylander R, Larsson L. Airborne bacteria, endotoxin and fungi in dust in poultry and swine confinement buildings. Am Ind Hyg Assoc J 1983;44:537-41.

25. Cormier Y, Duchaine C, Israël-Assayag E, Bédard G, Laviolette M, Dosman J. Effects of repeated swine buildings expo- 
sures on normal naive subjects. Eur Resp J 1997;10:1516-22.

26. Sjögren B, Wang Z, Larsson B-M, Larsson K, Larsson PH, Westerholm P. Increase in interleukin-6 and fibrinogen in peripheral blood after swine dust inhalation. Scand J Work Environ Health 1999;25:39-41.

27. Larsson K, Eklund A, Malmberg P, Belin L. Alterations in bronchoalveolar lavage fluid but not in lung function and bronchial responsiveness in swine confinement workers. Chest 1992;101:767-74.

28. Davies MJ, Gordon JL, Gearing AJH, Pigott R, Woolf N, Katz D, et al. The expression of the adhesion molecules ICAM-1, VCAM-1, PECAM, and E-selectin in human atherosclerosis. J Pathol 1993;171:223-9.

29. Hwang SJ, Ballantyne CM, Sharrett AR, Smith LC, Davis CE, Gotto AM Jr, et al. Circulating adhesion molecules VCAM-1, ICAM-1, and E-selectin in carotid atherosclerosis and incident coronary heart disease: the atherosclerosis risk in communities (ARIC) study. Circulation 1997;96:4219-25.

30. Malik I, Danesh J, Whincup P, Bhatia V, Papacosta O, Walker $\mathrm{M}$, et al. Soluble adhesion molecules and prediction of coronary heart disease: a prospective study and meta-analysis. Lancet 2001;Sep 22 358(9286):971-6.

31. Blankenberg S, Rupprecht HJ, Bickel C, Peetz D, Hafner G, Tiret L, et al. Circulating cell adhesion molecules and death in patients with coronary artery disease. Circulation 2001; 104(12):1336-42.

32. Sehgal PB. Interleukin-6: a regulator of plasma protein gene expression in hepatic and non-hepatic tissues. Mol Biol Med
1990;7:117-30.

33. Aase A, Almas R. The diffusion of cardiovascular disease in the Norwegian farming community: a combination of morbidity and mortality data. Soc Sci Med 1989;29:1027-33.

34. Austin SG, Huang N, Woernle CW. PMR study of mortality among Alabama workers and farmers. Am J Ind Med 1995;27:29-36.

35. Pomrehn PR, Wallace RB, Brumeister LF. Ischemic heart disease in Iowa farmers: the influence of lifestyle. J Am Med Assoc 1982;248:1073-6.

36. Jousilahti P, Vartiainen E, Tuomilehto J, Puska P. Occupation, fibrinogen and heart disease. Lancet 1997;349:506.

37. Hammar N, Alfredson L, Smedberg M, Ahlbom A. Differences in the incidence of myocardial infarction among occupational groups. Scand J Work Environ Health 1992;18:178-85.

38. Fleming LE, Gomez-Marin O, Zheng D, Ma F, Lee D. National Health Interview Survey mortality among US farmers and pesticide applicators. Am J Ind Med 2003;43:227-33.

39. Lee E, Burnett CA, Lalich N, Cameron LL, Sestito JP. Proportionate mortality of crop and livestock farmers in the United States, 1984-1993. Am J Ind Med 2002;N42:410-20.

40. Retterstol L, Eikvar L, Berg K. A twin study of C-reactive protein compared to other risk factors for coronary heart disease. Atherosclerosis 2003;169:279-82.

41. Das UN. Metabolic syndrome $\mathrm{x}$ : an inflammatory condition? Curr Hypertens Rep 2004;6:66-73.

Received for publication: 17 November 2003 